\title{
MICROLECTURAS: EN TORNO A ALGUNAS REFERENCIAS DE CERVANTES AL VINO
}

\author{
"Sucedió, pues, lector amantísimo, que \\ viniendo otros dos amigos y yo del famoso lugar \\ de Esquivias..."
}

A la fina erudición de María Rosa Lida debemos la averiguación de la huella posiblemente más concreta de Erasmo que se puede localizar en la obra de Cervantes. Lo contó hace años Américo Castro: pese a lo muy leído que estuviera por él el Modus confitendi y a la sensación de que le sonaban a algo familiar las medidas de Sancho contra los que o aguaban el vino, o lo vendían con nombre trocado, dice textualmente que nunca se habría atrevido a hablar a este propósito de influencia directa de Erasmo sobre el autor del Quijote sin la intervención decisiva de la insigne investigadora argentina ${ }^{1}$. Fue ésta quien, en carta personal, le llamó la atención sobre cómo, en el nombre de Altisidora, se advierte el eco del nombre de un vino -el vino de Auxerre, o Altissidorenssemencionado por Erasmo en el preciso momento en que está denunciando la perversa costumbre de hacer pasar, trocándole el nombre, un vino mediocre por otro de mejor calidad.

La identificación de esta reminiscencia textual puede interesar por varios motivos. En primer lugar, según parece obvio, por lo mismo que en el momento de su revelación interesó a Castro, a saber, no sólo porque aporta un argumento a favor de los que tuvieron que luchar por imponer la idea de que la obra de Cer-

${ }^{1}$ Nadie, que yo sepa, ha vuelto a conceder la menor importancia al dato, que aparece consignado en "Cómo veo ahora el Quijote", ensayo que sirve de introducción a la edición del Quijote publicada por Castro en 1971 (Magisterio Español, Madrid). A propósito del nombre de Altisidora y de la carta de María Rosa Lida, véanse las pp. 13 y 86. 
vantes lleva la huella de la influencia de Erasmo ${ }^{2}$, sino porque demuestra que esta influencia se extiende a terrenos insospechados y supone, además, un contacto íntimo incluso con obras hoy en día poco citadas por la crítica en su examen de dicha deuda. Igualmente interesa, según también advirtió Castro, por la luz que arroja sobre aspectos muy concretos de la creación cervantina y sobre el papel que en ella llegan a desempeñar unas reminiscencias textuales de asombrosa exactitud en su nada intrascendente detallismo. Si, por otra parte, pensamos en lo cargada de sentido que suele estar la onomástica cervantina ${ }^{3}$, puede verse como muy oportuna la lejana alusión al vino que se capta en el nombre de la atrevida muchacha que finge estar perdidamente enamorada de Don Quijote, para sumo gusto y contento de sus señores. Aunque esta desenvuelta figura femenina está tratada, por lo que a soltura de lengua se refiere, con una delicadeza que la acerca a la Preciosa decidora de una famosa buenaventura ${ }^{4}$, las libertades que se toma en su declaración de amor al caballero hacen de ella, en el terreno de la burla verbal, la mujer más "libre" del Quijote, particularidad que no deja de estar señalada, en los versos que canta, por una serie de inversiones carnavalescas en cierto sentido ya analizadas como tales por Rodríguez Marín ${ }^{5}$. Estos mo-

${ }^{2}$ Estoy pensando básicamente, al referirme al tiempo que costó persuadir de la realidad de contactos muy concretos, apoyados en careos textuales, en la paciente y minuciosa labor llevada a cabo desde hace años por ANTONIO VILANova. Véase ahora su iluminador ensayo "Erasmo, Sancho Panza y su amigo Don Quijote", Cervantes, 1988, Special Issue, Winter, pp. 43-92. Para la visión que actualmente se puede tener de la relación que aquí nos interesa, es por otra parte muy útil el artículo-reseña que, con motivo de la publicación del libro de Alban K. Forcione, Cervantes and the humanist vision: a study of four Exemplary Novels, Princeton University Press, Princeton, 1982, redactó para la misma revista Francisco Márquez Villanueva, "Erasmo y Cervantes, una vez más", Cervantes, 4 (1984), 123-137.

${ }^{3}$ Véanse, a este propósito, las aportaciones de Mauricio Molno, Cervantes: raices folklóricas, Gredos, Madrid, 1976, pp. 169-188; de DoMINIQUE REYRE, Dictionnaire des noms des personnages du 'Don Quichotte"' de Cervantes, Editions Hispaniques, Paris, 1980; y de Augustin Redondo, que vuelve a tocar el tema en su contribución al presente número y remite en nota (cf. n. 4) a varios artículos suyos en que se hallarán en particular comentarios sobre los nombres de Sancho Panza, Alonso Quijano, Aldonza Lorenzo, de la pareja de enamorados Antonomasia y don Clavijo, y del galeote-titiritero Ginés de PasamonteMaese Pedro.

${ }^{4}$ Remito a este propósito al sugestivo ensayo de Francisco MárqueZ VILlanueVa, "La buenaventura de Preciosa", NRFH, 34 (1985-86), 741-768.

${ }^{5}$ Véanse sus comentarios a algunas de las ocurrencias festivas de la de- 
mentos, en que se juega con gran delicadeza, pero también con descaro, con las leyes del decoro y con las exigencias que éstas solían imponer para la representación de lo femenino, pueden interpretarse, por lo tanto, como unos momentos de ligera infracción a las normas, equiparables en su esencia a los de una transitoria y ligera ebriedad.

Pero el detalle de que tan fijamente se le quedara grabado en la memoria a Cervantes el nombre de un exótico vino francés también tiene otro alcance. Es revelador del interés que, como a Erasmo y como a muchos humanistas, le suscita el tema del vino y de sus excelencias. En cierto sentido, a esto apunta Avalle-Arce cuando en una nota a su edición de las Novelas ejemplares señala que la lista de vinos italianos y españoles que se presenta en $E l$ licenciado Vidriera está superada en amplitud y variedad por la que figura en el Diálogo de las mujeres, de Juan de Espinosa ${ }^{6}$. Como

claración de amor de Altisidora, Clás cast, t. 7, p. 143. Esta visión del personaje de Altisidora es la que, en forma ligeramente más desarrollada, propongo en mi ensayo sobre "El erotismo en el Quijote: la voz femenina", que se recogerá en Edad de Oro, 9 (en prensa). Tengo en preparación otro artículo sobre esta curiosa figura femenina.

${ }^{6}$ Lo primero que presenta Juan de Espinosa es una verdadera ruta italiana de los vinos, que se inicia con los de Sicilia, Calabria y Nápoles y termina con los de Lombardía y Piamonte. En medio de esta lista de vinos italianos se deslizan, como en Cervantes y como es normal que pasara en el contexto de una Italia en contacto permanente con el Levante, unas alusiones a los vinos griegos y del Levante. Luego aparecen citados ocho vinos españoles y, tras haberse aludido genéricamente a "los claretes de Francia", se cierra la enumeración con una referencia a los vinos de Wittemberg y del Rin. Lo valioso de la alusión a los claretes franceses, en una época en que es escaso el interés que el vino francés suscita en España, ya fue destacado por Miguel HerreRO, en La vida española del Siglo de Oro, t. 1: Las bebidas, Madrid, 1933, p. 77. Esta enumeración tiene, pues, en primer lugar la particularidad de aparecer como un fiel reflejo de las andanzas personales del propio Espinosa, andanzas consignadas en forma muy sugestiva en el prólogo al lector escrito, al parecer, por un amigo suyo: "En los reinos, provincias y tierras que vio, como España, Francia, Sicilia, Nápoles, Toscana, Romaña, Lombardía y Piamonte, Flandes y Alemania, y otras diversas partes, con la peregrinación perficionó su prudencia, especialmente con los trabajos y peligros que por mar y por tierra pasó [...] tales, que si hubiesen particularmente de contarse, parecían pocos y pequeños, a su proporción, los que de Ulises celebra Homero" (cito, modernizando la ortografía, por la ed. de Ángela González Simón, CSIC, Madrid, 1946). Pero importa advertir que si dicha enumeración llama la atención por su extensión y su variedad, se encuentra en seguida superada por la que a continuación está dedicada a la celebración de las fuentes por aquel de los dos interlocutores que, en el diálogo de Espinosa, está asumiendo la defensa del 
siempre ocurre, resulta interesante ver cómo un tema que muchos desarrollan se carga, sègún los casos, de resonancias más o menos personales. Me propongo ilustrar esto con tres ejemplos sacados de la obra de Cervantes, mostrando cómo el tratamiento de algo aparentemente tan anecdótico como son unas alusiones a unos vinos cuyos nombres se especifican se combina con la exposición de ideas básicas para la comprensión de su pensamiento.

La referencia al vino de Candía que encontramos en la segunda de las dos comidas que se celebran al comienzo del Persiles es a este propósito singularmente elocuente en su brevedad. La transición del mundo bárbaro ajeno a toda presencia civilizadora a otro, agreste todavía, pero con huellas de dicha presencia - la del español instalado entre bárbaros y que ha enseñado su lengua a su mujer y a sus hijos-, se señala en particular por médio de un contraste entre dos comidas. Ambas se toman en el suelo y sobre pieles de animales ${ }^{7}$. Pero todo el primor que son capaces de ostentar los bárbaros del comienzo de la obra se gasta, precisamente, en la preparación de estas pieles, unas pieles "curtidas, limpias y lisas" sobre las que, en cambio, las frutas secas de la comida son arrojadas y tendidas "sin concierto ni policía alguna". En la etapa subsiguiente, al revés, la bárbara Riela y sus hijos se desvelan por atender lo mejor posible a sus huéspedes, actitud que supone el reconocimiento previo, o cierto reconocimiento al menos, de los valores básicos de concierto y policía, ajenos a quienes no han estado, como ellos, en contacto con la civilización. De ahí que a propósito de la comida que se celebra en su cueva no parezca impropia la introducción de un contrapunto que remite, aunque sea para referirse a ellos por preterición, a los más exquisitos refinamientos de Italia y Grecia:

agua. La línea argumentativa seguida en el diálogo es en efecto la de una contienda, ya no, como en la Edad Media, entre el agua y el vino, sino entre dos amigos, el primero de los cuales, Philodoxo, celebra las excelencias del vino, mientras el segundo, Philalithes, está procurando demostrarle la superioridad del agua. La mayor extensión dada a la enumeración de las fuentes es un claro indicio del lado al que se inclinan las preferencias del autor (sobre lo que ideológicamente significa esta defensa de la sobriedad, véanse los ahora imprescindibles comentarios de JACQUELINE FERRERAS, Les dialogues espagnols du XVT siècle ou l'expression littéraire d'une nouvelle conscience, Atelier National de Reproduction des Thèses-Didier Erudition, Paris, 1985, t. 1, pp. 521-536).

7 Miguel de Cervantes, Los trabajos de Persiles y Sigismunda, ed. Juan Bautista Avalle-Arce, Castalia, Madrid, 1969, pp. 65 y 71. Cito en adelante por esta edición. 
Las vajillas que en la cena sirvieron ni fueron de plata ni de Pisa: las manos de la bárbara y bárbaro pequeño fueron los platos, y unas cortezas de árboles, un poco más agradables que de corcho ${ }^{8}$ fueron los vasos. Quedóse Candía lejos y sirvió en su lugar agua pura, limpia y frigidísima.

Importa observar que, incluso si en una etapa de su viaje se les brinda la oportunidad de celebrar excepcionalmente una comida acompañada de "generosos vinos", el viaje de Norte a Sur de los peregrinos del Persiles no acortará las distancias que de este modo quedaron sentadas y que poco tienen que ver, en realidad, con la consideración exclusiva de unas distancias físicas. Dados los valores de los que es portadora la obra, el mundo en que se tiene acceso a los refinamientos de la vajilla de plata y de la cerámica pisana, el mundo de los que se relajan catando el exquisito vino de Candía, es un mundo destinado a permanecer ajeno al pequeño grupo de los que acompañan a Periandro y Auristela.

El vino de Candía también aparece citado en El licenciado Vidriera, pero con diferencias textuales y contextuales que dan claramente a entender cuán lejos de la peregrinación del Persiles quedan las andanzas de Tomás Rodaja. A Tomás y a los soldados en cuya compañía viaja les basta, en efecto, llegar a Génova y pisar el suelo de Italia para que en seguida esté a su alcance no sólo este famoso vino griego, sino una lista relativamente copiosa de vinos dignos todos, menos el último allí mencionado, de competir en excelencia con él:

Allí conocieron la suavidad del Treviano, el valor del Montefrascón, la fuerza del Asperino, la generosidad de los dos griegos Candía y Soma, la grandeza del de las Cinco Viñas, la dulzura y apaci-

${ }^{8}$ La rusticidad del vaso de corcho está cargada, en la obra de Cervantes, de un simbolismo ambivalente. Vemos que, en la segunda comida del Persiles, se considera como un rasgo positivo que en su lugar sirvan unas cortezas de árboles, se entiende que más finas y delicadas. En la Isla de las Ermitas, el dato de que se están aprovechando estos rústicos recipientes se matiza reiteradamente, al indicarse que los vasos de corcho de la comida están "con maestría labrados" y que las "puras y limpias aguas" que en ellos se sirven muestran su claridad, "a pesar de la parda color de los corchos" (p. 260). En un polo rigurosamente opuesto, tenemos el famoso y grotesco "corcho de colmena" de Rinconete, que es uno de los muchos indicios por medio de los cuales queda señalada y denunciada la barbarie de los secuaces de Monipodio.

${ }^{9}$ Véase, en especial, p. 123. 
bilidad de la señora Guarnacha, la rusticidad de la Chéntola, sin que entre todos estos señores osase parecer la bajeza del Romanesco.

Todo, en este inventario, indica que estamos en una situación rigurosamente opuesta a la del Persiles. Lo da por supuesto a entender el mero hecho de que, en lugar de quedar simbólicamente lejano, el mundo de los vinos exquisitos resulte ahora ${ }^{10}$ de tan fácil acceso. En la medida en que es ahora asequible, se entra a su propósito en particularidades que lo presentan en su polifacética variedad, dotando a cada uno de los vinos que entran en la lista de una personalidad que lo distingue del vecino, cosa que también contrasta con la escueta y exclusiva referencia a Candía que encontramos en el Persiles. Incluso puede observarse que esta designación metonímica, que en la gran novela alegórica sirve para remitir por antomasia al mundo de los vinos finos, ni siquiera se considera suficiente en El licenciado Vidriera para introducir, como un lujo más, la correspondiente nota griega en medio de una enumeración que sólo consta, por otra parte, de nombres de vinos italianos, puesto que junto al de Candía aparece ahora citado el de Soma. Otro detalle revelador es, por fin, que en la lista en que el vino de Candía ya no figura sino como un ítem entre otros, el uso cervantino de la preterición, dando según es frecuente la clave simbólica del texto, resalta que el único vino que se considera indigno de ser servido allí junto a los demás queda excluido por "bajo" y de insuficiente prestigio.

Pero la particularidad más digna de interés de la lista de vinos italogriegos de El licenciado Vidriera tal vez no sea ninguna de las anteriormente mencionadas, sino la curiosa modalidad de su inserción en el relato. Esta enumeración, que al comienzo parece estar asumida por la voz de un narrador omnisciente, cambia en efecto repentinamente de estatuto narrativo, cuando nos percatamos de que ha correspondido en realidad a la "reseña" que se encargó de presentar al capitán y a sus camaradas el dueño de la hostería en la que éstos se encuentran. Sucede esto en el preciso momento en que la susodicha lista de vinos italogriegos está a punto de complementarse con otra, compuesta por su parte de vinos españoles:

${ }^{10} \mathrm{Al}$ hacer uso de este adverbio, no me estoy refiriendo al orden en que cabe suponer que fueron escritos los dos textos cervantinos que estoy examinando, sino al adoptado por mí para su estudio. 
Y habiendo hecho el huésped la reseña de tantos y tan diferentes vinos, se ofreció a hacer parecer allí, sin usar de tropelías, ni como pintados en mapa, sino real y verdaderamente, a Madrigal, Coca, Alaejos, y a la Imperial más que Real Ciudad, recámara del dios de la risa; ofreció a Esquivias, a Alanís, a Cazalla, Guadalcanal y la Membrilla, sin que se le olvidase de Rivadavia y Descargamaría [... ]

La revelación de que, en el fragmento que nos interesa, las fronteras del relato no son las que habíamos creído, lleva a leer a nueva luz la alusión a los "conocimientos" que Tomás y sus compañeros adquieren en la hostería genovesa adonde van a parar tras las zozobras de su azaroso viaje marítimo. Aunque a propósito de su repertorio de vinos españoles insiste el huésped en la conformidad de sus obras con sus palabras, y aunque esta conformidad también se pone de realce en la conclusión que recibe este báquico episodio ("Finalmente, más vinos nombró el huésped, y más les dio, que pudo tener en sus bodegas el mismo Baco'), no deja de tener interés que la iniciación de Tomás se nos presente básicamente en su faceta verbal.

Cervantes se está situando de este modo en una vieja tradición, la del "festín de palabras" recordada por Jean-François Revel en un clásico ensayo ${ }^{11}$, con la paradójica circunstancia de que el "gaudeamus de palabras" que encontramos en su novela nos lo presenta un huésped que, a diferencia de sus homólogos de la tradición festiva, está dispuesto a mostrar que sus obras pueden estar a la altura de sus promesas ${ }^{12}$. No se ha de perder de vista que lo que se elude, al ponerse con tanto ahínco el acento en los ofrecimientos supuestamente seguidos de efecto de un huésped fuera de la norma, es una presentación más cruda del tema de la ebriedad, escabroso entre todos a propósito de un protagonista tan desencarnado como lo es el futuro Vidriera. Gracias a la mediación del huésped y a sus deslumbrantes "reseñas", el tema no apare-

11 Un festin en paroles. Histoire littéraire de la sensibilité gastronomique de l'Antiquité à nos jours, Pauvert, Paris, 1979 (el libro existe ahora en colección de bolsillo). La expresión "festín de palabras" está tomada de Ateneo. El mismo tema ha vuelto a ser tratado con brillo por Michel JEANNERET, Des mets et des mots. Banquets et propos de table à la Renaissance, José Corti, Paris, 1987.

${ }^{12}$ La tradición del huésped jactancioso, que el lector podrá ver ilustrada en una carta latina del doctor Laguna de 1548, reproducida por BATAILLON en "Andrés Laguna. Contes à la première personne", $B H i, 58$ (1956), p. 206, es la que da sal a las paradojas de la primera comida de Don Quijote y es abiertamente aprovechada por Cervantes a propósito de la penúltima venta visitada por Sancho y por Don Quijote (II, 59). 
ce allí tratado más que de un modo indirecto, exactamente como en forma indirecta también estuvo tratado, gracias a la mediación del capitán don Diego de Valdivia, el tema igualmente escabroso de la arrogancia del soldado español estacionado en Italia y de sus exigencias en materia de regalo y gastronomía ("dibujóle dulce y puntualmente el aconcha, patrón: pasa acá, manigoldo; venga la macarela, li polastri, e li macarroni'). Paralelo que lleva a observar con cuán rigurosa simetría el viaje que de Cartagena a Génova está haciendo Tomás junto con los soldados se encuentra enmarcado por las promesas del capitán, apoyadas en reminiscencias del pasado, y por los ofrecimientos que en forma de "reseñas" está haciendo el huésped de la hostería genovesa. Mientras que en aquéllas desciende el capitán a pormenores muy concretos acerca de la parte "sólida" de las experiencias gastronómicas asociadas en su recuerdo con su permanencia anterior en Italia, éstas toman la forma de una celebración del vino hecha con marcado virtuosismo y tal vez reminiscente de la tradición misma del ditirambo. No deja de ser significativo que Tomás sólo se encuentre unido al grupo capitaneado por don Diego para un gaudeamus que se sitúa exclusivamente en este segundo terreno. Tampoco lo es que, mientras la orden terminante de que se traigan en seguida los pollos y los macarrones aparece unida a una inequívoca referencia a la vida libre del soldado estacionado en Italia, la alusión al gaudeamus que los soldados se disponen a celebrar en Génova, y en el que participa Tomás, está precedida de dos indicaciones que obran a modo de circunstancias atenuantes, puesto que además de señalarse que, antes de ir a parar en una hostería, el capitán y sus acompañantes han cumplido con sus obligaciones religiosas, se indica que, dadas las dificultades por las que acaban de pasar, tienen bien merecido el refrigerio que se van a tomar:

En fin, trasnochados, mojados y con ojeras, llegaron a la hermosa y bellísima ciudad de Génova, y desembarcándose en su recogido mandrache, después de haber visitado una iglesia, dio el capitán con todos sus camaradas en una hostería, donde pusieron en olvido todas las borrascas pasadas con el presente gaudeamus.

La situación frente a la cual nos encontramos es, pues, la siguiente: el tema del ágape, y el complementario de las libaciones se cruzan con la trayectoria de Tomás en el preciso momento en que ésta cambia de orientación, a raíz de su encuentro con los representantes de la vida familiar. Pese a las notas festivas y al brillo 
con que está tratado, el empeño de Cervantes en presentarlo desligado de la persona del protagonista, descargando en particular a Tomás de todo compromiso personal en la adquisición de unos "conocimientos"' bien distintos de los adquiridos por él en los ambientes universitarios, es o parece ser un indicio de las íntimas reservas que este tema doble le inspira.

Es cierto que estas enumeraciones de tema gastronómico o báquico se integran, por otra otra parte, en el corpus más extenso de las enumeraciones que se confunden prácticamente con la trama de la novela, desde el momento en que comienza a tocarse en ella el tema de la vida del soldado en Italia, hasta el del regreso de Tomás a España ${ }^{13}$. Pero, en relación con esto y en apoyo de la idea de que, pese a su envoltura festiva, las alusiones al ágape y a las libaciones no están exentas de segundas intenciones críticas, observaré que no todas las enumeraciones que sirven de soporte a la narración durante la odisea de Tomás tienen el mismo sentido. Sólo a partir del momento en que está significativamente introducido el tema de la admiración ${ }^{14}$, con motivo de la alusión al rubio cabello de las genovesas, es lícito hablar, según se ha hecho, de la metamorfosis del futuro Vidriera en lente a través del cual se nos presentan una serie de impresiones de Italia ${ }^{15}$. Las enumeraciones anteriores a este momento clave, lejos de remitir exclusivamente a lo que Tomás ve, remiten también al mundo tal como se lo presentan los demás -el capitán y el huésped genovés-, e incluso tal como es e intencionadamente deja de presentárselo quien tiene interés en silenciar algunos de sus aspectos. A diferencia de las otras, estas enumeraciones del principio están todas más o menos abiertamente cargadas de sentido crítico. Esta intención crítica se advierte claramente en las ya aludidas alabanzas de la vida libre que disfruta el soldado español en Italia, en las que es reconocible la huella de denuncias y de críticas que se convierten prácticamente en tópicos a lo largo del siglo

${ }^{13}$ Sobre estas enumeraciones ha llamado la atención, aunque desde una perspectiva exclusivamente formal, JoRGE URRUTIA en "Narración y bloques narrativos en Cervantes", Estudios sobre el Siglo de Oro. Homenaje al profesor Francisco Ynduráin, Editora Nacional, Madrid, 1984, p. 517; y "Paralelismo formal en El licenciado Vidriera", Edad de Oro, 3 (1984), 294-297.

${ }^{14}$ Remito, a propósito de este concepto, a la exposición de EDWARD C. RiLey, Teoría de la novela en Cervantes, Taurus, Madrid, 1966, pp. 148-156.

${ }^{15}$ Sobre la transparencia de Tomás Rodaja, véase RUTH el SAfFar, Novel to romance. A study of Cervantes's "Novelas ejemplares", John Hopkins University Press, Baltimore, 1974, p. 55. 
Xvi. También se capta con toda claridad en la revelación de cómo es la otra cara de la vida militar, mucho menos halagüeña que la presentada con comunicativo entusiasmo por don Diego de Valdivia ${ }^{16}$. Donde de un modo más abierto se le da rienda suelta a la indignación es en la panorámica presentación del "cuerpo enfermo"' del ejército español ${ }^{17}$, con las - para entonces- consabidas protestas contra la corrupción de la administración y de los mandos y contra los desmanes de la tropa. Donde, en cambio, la crítica parece estar teñida de notas festivas es en la también panorámica presentación de los inconvenientes y de las molestias que trae consigo la vida de la galera, con claras reminiscencias de las quejas entre serias y humorísticas del Arte de marear de Antonio de Guevara ${ }^{18}$.

Desde esta perspectiva, el fragmento de interpretación más problemática es, sin lugar a dudas, el que aquí ha servido de punto de partida para estas reflexiones sobre El licenciado Vidriera, o sea, aquel que parece estar colocado bajo la advocación del dios de la risa y en que se celebran unas bodas medio oníricas entre Italia y España. La palabra "bodas" no está empleada aquí de un modo gratuito, en la medida en que me parece plausible que en el ditirambo cervantino influyera el modelo de algún elogio festivo del vino, del tipo del que nos ha llegado a través del mediocre poema de Rodríguez de Ardila, editado por Rodríguez Marín ${ }^{19}$.

16 " Puso las alabanzas en el cielo de la vida libre del soldado y de la libertad de Italia; pero no le dijo nada del frío de las centinelas, del peligro de los asaltos, del espanto de las batallas, del hambre de los cercos, de la ruina de las minas, con otras cosas de este jaez, que algunos las toman y tienen por añadiduras del peso de la soldadesca, y son la carga principal de ella"', Novelas ejemplares, ed. Juan Bautista Avalle-Arce, Castalia, Madrid, 1982, t. 2, p. 106. Huelga decir que en esta enumeración también se acumulan tópicos sobre la dura vida del soldado.

17 "Allí notó Tomás la autoridad de los comisarios, la incomodidad de algunos capitanes, la solicitud de los aposentadores, la industria y cuenta de los pagadores, las quejas de los pueblos, el rescatar de las boletas, las insolencias de los bisoños, las pendencias dè los huéspedes, el pedir bagajes más de los necesarios, y, finalmente, la necesidad casi precisa de hacer todo aquello que notaba y mal le parecía" (p. 108).

18 "Allí se embarcaron en cuatro galeras de Nápoles, y allí notó también Tomás Rodaja la extraña vida de aquellas marítimas casas, adonde lo más del tiempo maltratan las chinches, roban los forzados, enfadan los marineros, destruyen los ratones y fatigan las maretas"' (p. 109).

19 Baco y sus bodas en España. Poemita jocoserio de Pedro Rodríguez de Ardila, anotado por Francisco Rodríguez Marín, Madrid, 1933. 
A este aspecto entre mítico y festivo, y a él exclusivamente, parece remitir la frase de enlace mediante la cual se pasa de la alusión a las míticas bodegas de un huésped capaz de competir con el mismo Baco, a la celebración de los rubios cabellos de las genovesas: "Admiráronle también al buen Tomás los rubios cabellos de las genovesas [...]". Lo que parece indicar esta transición a primera vista desconcertante es que la admiración de Tomás, aunque no mencionada en lo que precede, es en realidad algo que se extiende al conjunto de sus experiencias italianas y que estuvo ya suscitada por las "reseñas" del dueño de la hostería. Todo esto se compagina muy mal con la idea, antes expresa$\mathrm{da}$, de que la línea crítica que se introdujo en el texto con las alusiones a la vida regalada que el soldado español acostumbra llevar en Italia, sigue tenuemente presente en el momento de la ditirámbica presentación de los vinos italogriegos y españoles.

Creo, sin embargo, que no sólo el paralelo ya esbozado con el Persiles, sino el que sugiere el examen de otros fragmentos de la obra cervantina autorizan a pensar que estas enumeraciones ofrecen en realidad dos vertientes, la una alegre y regocijada, crítica la otra y acompañada en su expresión de las reservas a las que ya me he referido. Al decir esto, estoy pensando en primer lugar en las famosísimas escenas de Rinconete y Cortadillo y del capítulo 54 de la Segunda parte del Quijote, en que, según es sabido, se celebran unos gaudeamus que se distinguen en particular por la copia con que en ellos menudean los tragos ${ }^{20}$. En otros lugares he defendido la idea de que sólo una visión totalmente descontextualizada de ambas escenas puede llevar a enfocarlas exclusivamente como unas escenas alegres y carentes de sentido crítico $^{21}$. Por debajo de lo que sólo aparentemente tiene el aspecto de una goliárdica celebración de buenos bocados y mejores tragos, quien sitúa el texto en su contexto reconoce la presencia de una denuncia, y de una denuncia bastante dura y corrosiva, de seres vistos en su conjunto como una verdadera gangrena del cuerpo social. Es de sentir que, por lo que se refiere al almuerzo de

${ }^{20}$ Me parece de suma importancia que, a diferencia de lo que ocurre en la presentación de las dos escenas báquicas que acabo de mencionar, no tengamos a propósito del gaudeamus que Tomás y sus compañeros celebran en Génova la menor alusión concreta al consumo directo del vino ni a la actitud de los bebedores.

${ }^{21}$ Véanse respectivamente "Afición de los extranjeros al vino y al jamón: nota sobre el sentido de una síntesis cervantina", $N R F H, 22$ (1973), 321-328, y "Monipodio revisited", $C H$ (7), pp. 603-611. 
Rinconete y Cortadillo, la tendencia dominante de la crítica haya consistido en seguir ciegamente a Menéndez y Pelayo, y a esbozar improcedentes confrontaciones con las poco apetitosas comidas del Guzmán, con lo cual lo que se ha conseguido es que ni el almuerzo que se celebra en el patio de Monipodio ni las comidas del Guzmán hayan sido correctamente valoradas en sus respectivos aspectos simbólicos. En cuanto a la comida que Sancho toma en compañía de Ricote y de un grupo de falsos peregrinos francotudescos, lo que explica que, pese a la transparencia de ciertos indicios, muchos se hayan negado a situarla en la tradición que le corresponde y que, como en el caso del almuerzo del Rinconete, es la del banquete inmoral de parásitos, es el arraigado prejuicio de que el problema morisco está en este capítulo del Quijote tratado con comprensiva simpatía. Ha de reconocerse que, en este segundo caso, la participación de Sancho en el banquete es algo que ha contribuido a dificultar su interpretación, dado el carácter reductor de la visión de conjunto que se suele tener de su relación con la comida ${ }^{22}$. Es en particular muy insuficiente la atención que han recibido los acentos ascéticos de algunas de sus más destacadas manifestaciones de independencia. Aunque esta corriente está presente en la obra desde el momento mismo de la aparición de Sancho en ella - piénsese en las palabras mediante las cuales se autodefine como un auténtico "villano en su rincón", cuando su amo le insta a que se siente junto a él, durante la primera cena que toman en común en medio de los pastores ${ }^{23}-$, donde más plenamente se expresa es en el Quijote de 1615. El tema del ascetismo sanchesco acaba de estar ilustrado con singular relieve, por medio las palabras de despedida dirigidas por él a los insulanos de Barataria, cuando su camino se cruza con el de los falsos peregrinos en cuya compañía viaja Ricote. En la medida en que están

${ }^{22}$ De esto he hablado, aunque de un modo que considero todavía fragmentario, en "L'ideólogie de la poule au pot: les avatars de la olla podrida", trabajo que se presentó en el último coloquio organizado por el Centre de Recherche sur l'Espagne des $\mathrm{XVI}^{\mathrm{e}}$ et XVII ${ }^{\mathrm{e}}$ siècles (París, octubre de 1988), cuyas Actas están en prensa.

23 “- ¿Gran merced! — dijo Sancho-, pero sé decir a vuestra merced que como yo tuviese bien de comer, tan bien y mejor me lo comería en pie y a mis solas como sentado a par de un emperador. Y aun, si va a decir verdad, mucho mejor me sabe lo que como en mi rincón sin melindres ni respetos, aunque sean pan y cebolla, que los gallipavos de otras mesas donde me sea forzoso mascar despacio, beber poco, limpiarme a menudo, no estornudar ni toser si me viene gana, ni hacer otras cosas que la soledad y libertad traen consigo", I, 11, ed. Luis A. Murillo, Castalia, Madrid, t. 1, p. 154. 
entonces para él todavía frescos los sinsabores y los trabajos de la experiencia anterior, puede afirmarse que cuando se le presenta el gaudeamus que va a compartir con el poco recomendable grupo con el que se cruza, tiene éste con el de Tomás el punto común de que en ambos casos la experiencia báquica permite poner en olvido las borrascas pasadas.

Se observará que el contrapunto de la vida ascética, acompañado por cierto de notas festivas, también está presente en el regocijado episodio en que Sancho comparte con el escudero del Caballero del Bosque la gigantesca empanada y el vino que éste trae consigo. Quien se encarga entonces de introducirlo es el propio Sancho, al destacar cuando descubre estas provisiones cuán cruelmente entran en contraste con las que él mismo suele llevar ${ }^{24}$. El detalle confirma que, incluso en el contexto en que su tratamiento parece más festivo, el tema de la exaltación báquica necesita, para estar desarrollado en relación con la persona de Sancho, que de algún modo aparezca precedido de una alusión de carácter penitencial.

La perspectiva dialéctica desde la que estoy sugiriendo que se ha de replantear el problema de las alusiones de Cervantes al vino me llevará a hablar, en último lugar, de la que encabeza el famoso prólogo al Persiles. Lo que me incita a proponer que esta referencia de Cervantes a Esquivias se deje de interpretar exclusivamente como un humorístico homenaje a un lugar con el que sabemos que Cervantes estaba personalmente relacionado es la consideración de lo que puede significar esta alusión inicial al vino, en un texto cuyo autor, además de despedirse para siempre de los donaires, alude con una sonrisa a la sed inextinguible que le aqueja y que, según sabe e indica, habrá de causar su muerte.

El prólogo al Persiles es un texto en el que se juega con tanto refinamiento como en otros preliminares cervantinos con una muy visible serie de tópicos. Mario Socrate, en su clásico y sutilísimo ensayo, destacó cómo se está jugando allí con el tópico del homo

\footnotetext{
24 “"-Vuestra merced sí que es escudero fiel y legal, moliente y corriente, magnífico y grande, como lo muestra este banquete [.. .]; y no como yo, mezquino y malaventurado, que sólo traigo en mis alforjas un poco de queso tan duro, que pueden descalabrar con ello a un gigante: a quien hacen compañía cuatro docenas de algarrobas y otras tantas de avellanas y nueces, mercedes a la estrecheza de mi dueño, y a la opinión que tiene y orden que guarda de que los caballeros andantes no se han de mantener y sustentar sino con frutas secas y con las yerbas del campo", II, 13, t. 2, p. 132.
} 
viator $^{25}$. Este tópico se cruza con el del puer-senex, recientemente estudiado por Eduardo Urbina en su relación con el personaje de Don Quijote ${ }^{26}$. Incluso para el abrupto comienzo, "Sucedió, pues,...' se han de tener presentes los útiles comentarios de Lore Terracini sobre la larga tradición del ibam forte cuyo eco se capta en muchos de los momentos claves de la obra de Cervantes ${ }^{27}$. Dos son los tópicos que creo que hay que agregar a esta lista: el del contraste entre el agua y el vino, y el del contraste agua dulce vs. agua salada, al que remite la parte rítmicamente nostálgica del diagnóstico del estudiante (“[ . . . ] que no la sanará toda el agua del mar Océano que dulcemente se bebiese')'. El detalle mismo de la reduplicación de los contrastes en los que figura el agua corrobora, a mi modo de ver, que nos encontramos frente a un juego de carácter estoico, muy en la línea de las alusiones a la manquedad personal de Cervantes que encontramos con cierta abundancia en el prólogo de las Novelas ejemplares.

Me atrevo a decir que puedo contar, para la interpretación que estoy proponiendo, con el inesperado apoyo de Cernuda. Es muy conocido el juego intertextual que en el patético poema titulado Despedida le lleva, luego de haber invertido al comienzo la letra de un tango famoso ${ }^{28}$ a citar reelaborándola apenas la despedida cervantina del Persiles:

Adiós, adiós, manojos de gracias y donaires.

Que yo pronto he de irme, confiado,

Adonde anudado el roto hilo, diga y haga

Lo que aquí falta, lo que a tiempo decir y hacer aquí no supe.

Adiós, adiós, compañeros imposibles,

Que ya tan solo aprendo

A morir, deseando p. 79 .

${ }^{25}$ Prologhi al "Don Chisciotte", Marsilio Editori, Venezia-Padova, 1974,

26 “Don Quijote, puer-senex: un tópico y su transformación paródica en el Quijote", JHPh, 12 (1988), 127-138.

${ }^{27}$ En Lingua come problema nella letteratura spagnola del Cinquecento (con una frangia cervantina), Stampatori, Torino, 1979, p. 291. Agradezco a mi amiga María Cruz García de Enterría el haberme facilitado una copia de este magnífico libro.

${ }^{28}$ Digo que es conocido este juego intertextual pensando en el comentario que se le dedica en obra tan poco confidencial como la guía de lectura, por otra parte muy bien hecha de LuIS MARISTANY, Guias Laia de Literatura 5, Laia, Barcelona, 1982, p. 91. 
Veros de nuevo, hermosos igualmente

En alguna otra vida.

Si es conocidísima, según acabo de recordar, esta reelaboración por Cernuda de la famosa despedida cervantina del prólogo al Persiles, nadie, que yo sepa, ha observado que se encuentra precedida de la siguiente celebración nostálgica del convivio:

Qué dulce hubiera sido

En vuestra compañía vivir un tiempo:

Bañarse juntos en aguas de una playa caliente,

Compartir bebida y alimento en una mesa $[\ldots]$

No me parece mal que un trabajo que se inició haciendo hincapié en lo significativo del secreto homenaje a Erasmo que se capta en el nombre de Altisidora termine incitando a leer esta alusión de Cernuda a la bebida y al alimento compartidos como otra faceta de su homenaje a Cervantes, y como muestra de la incomparable lección que en el terreno de la hermenéutica nos dan siempre los poetas.

Monique Joly 